\title{
UAV AND CLOSE-RANGE PHOTOGRAMMETRY TO SUPPORT GEO-MECHANICAL ANALYSIS IN SAFETY ROAD MANAGEMENT: THE “VALLONE D'ELVA" ROAD
}

\author{
E. Pontoglio ${ }^{1,1 *}$, E. Colucci ${ }^{1}$, A. Lingua ${ }^{1}$, P. Maschio ${ }^{1}$, M.R. Migliazza ${ }^{2}$, C. Scavia ${ }^{2}$, \\ ${ }^{1}$ Department of Environmental, Land and Infrastructure Engineering (DIATI) - Politecnico di Torino C.so Duca degli Abruzzi 24, 10129, \\ Torino (Italy) (emanuele.pontoglio, elisabetta.colucci, andrea.lingua, paolo.maschio)@ polito.it \\ ${ }^{2}$ Department of Structural, Geotechnical and Building Engineering (DISEG), Politecnico di Torino C.so Duca degli Abruzzi 24, 10129, \\ Torino (Italy) (maria.migliazza, claudio.scavia)@polito.it
}

\section{Commission II, WG II/10}

KEYWORDS: Landslide Hazard, Geomechanics Analysis, Photogrammetry, Multiscale Approach, DTMs, Orthophotos.

\begin{abstract}
:
In the last decades, the development of geomatics and geomechanics techniques integration in the environmental field permits to obtain more detailed and accurate results, reducing the survey costs. The aim of the present work was aimed to apply these innovative combined methods and techniques in order to gain a detailed analysis of landslide hazard and on the stability condition of rocky slopes, to get useful information for subsequent design and feasibility planning of Vallone d'Elva road. During two different surveys period, geostructural surveys were carried out in situ (i.e. spatial orientation of discontinuity planes, their spacing and persistence), associated with geomatics surveys using drones (UAV technique - Unmanned Aerial Vehicle) and terrestrial photogrammetric technique to get high-resolution images of the rockwalls along the road in areas with complex orography and inaccessible. Their data processing has allowed the generation of different kind of data at different scales, like some 3D dense point clouds with a huge definition, which have been used to generate threedimensional surfaces models. This procedure has allowed obtaining DSM (Digital Surface Model), DTMs (Digital Terrain Models) and orthophotos with centimetre resolution (mean $4 \mathrm{~cm}$ ). Moreover, to identify the geomechanical rockmasses features, have been computed a new photogrammetric product on 16 specific rockwall sites along the road: "vertical orthophotos", with details of few mm. Besides, over then twenty detailed DTMs of rockwalls along the entire road have been generated to measure plane orientation, spacing and other geometrical characteristics of outcropping rock masses, which have been statistically collected and analysed.
\end{abstract}

\section{INTRODUCTION AND CASE STUDY}

\subsection{Introduction}

In last decades, the study of environmental safety and management in Italy has had a considerable growth, born from the need to analyse more often environmental hazard with difficult accessible places and/or for which a very detailed overall analysis framework was needed.

In this perspective, new and different detection technologies have been developed and employed in artificial (Masiero et al., 2019) and environmental issues, such as image-based UAV (Unmanned Aerial Vehicle) technology (Ahmad \& Samad, 2010; Watts et al., 2012) and terrestrial photogrammetry (Jiang et al., 2008), associated with traditional topographic techniques such as GNSS-RTK technology. These new technologies and their integrations guarantee a better environmental criticality understanding, providing a very detailed mapping of the investigated site. The validity of these technologies was the basis of the photogrammetric and geomechanical study (Mancini et al., 2017; Piras, Taddia, et al., 2017) applied to the case study presented in this article, which to enhance the environmentterritory system from a safety point of view, using a multi-sensor approach (Castagnetti et al., 2013, 2014) on the Vallone d'Elva road in Piedmont (Italy), investigating the persistent rocky slopes vulnerability along SP104 road, still closed to traffic, leading to Elva hamlets.

In the literature, monitoring and documenting of landslides case studies in complex and inaccessible environments using geomatics technologies are manifold (Artese et al., 2014; Corsini et al., 2013; Spreafico et al., 2015), testifying the importance of this issue. Given this orography complexity, an "ad hoc" acquisition and processing methodologies have been developed, to generate the 3D model, integrating UAV and terrestrial photogrammetric techniques both. Nadiral and oblique images (Aicardi et al., 2016) have been acquired, in order to obtain a more exhaustive and correct 3D model (complete, accurate, and precise) for the greater landslide hazard as witnessed by the event occurred in 2014, which led to the definitive closure of the route. $\mathrm{UAV}$ and terrestrial photogrammetry high-resolution images were analysed using photogrammetric software AMS (Agisoft Metashape Professional) through the SfM (Structure for Motion) computation (Caroti et al., 2015; Chiabrando et al., 2015), generating surface data at different survey scales with a multiscale approach (Bemis et al., 2014; Kalbermatten et al., 2012; Marceau \& Hay, 1999), obtaining 3D dense point clouds and surfaces at different details level along the road axis, or focusing on the landslide event. The tridimensional surface models obtained have been allowed to generate some DSMs (Digital Surface Models) and orthophotos; further analyses were carried out to classify the vegetation on rocky slopes, generating many high-resolution DTMs (Digital Terrain Models) useful to safety planning and landslide risk analysis ( $\mathrm{Li}$ et al., 2004; Niethammer et al., 2012).

Moreover, high resolution terrestrial photogrammetric survey of the whole road has been performed, obtaining dense point clouds and vertical orthophotos, useful for geostructural analysis and landscape security purposes. The vertical orthophotos have been computed on 20 rock masses analyzed with the on-field traditional geomechanical survey, to perform them and to offer

\footnotetext{
1* Corresponding author
} 
an even more detailed product at the technicians for feasibility and safety planning.

Every product has been georeferenced using the GNSS-RTK survey on horizontal (on the street) and vertical (on the rocky walls) markers along Vallone d'Elva road. To cover all ten kilometres road envelop, the survey has been divided in three different areas, namely "High part of Road (HR)", "Low part of Road (LR)" and "Large Landslide (LL)".

The unstable conditions along the Vallone d'Elva road are mainly due to two different phenomena: the first one represents the biggest landslide occurred and it is definable as a planar sliding of a big rock volume (more than $200 \mathrm{~m}^{3}$ ) along the bedding plane characterizing the rock formation; the others are spread along the road and due to the detachment from the hanging rock wall of single block or group of blocks falling directly on the road. The definition of the stability conditions needs, at first, to identify the kinematic mechanism (planar and wedge sliding, overturning, ...) of potentially unstable blocks formed by the intersection of the discontinuity surfaces and secondly, the estimate of the shear strength of the surfaces themselves. The first activity was carried out by means of geostructural surveys that allow the definition of spatial orientation of discontinuity planes, their spacing and persistence. Usually these surveys have been made along scanlines placed directly on the rock wall and using geological compass. In this case, block detachments occur so often along the entire road, in such a way do not allow this operation under safety conditions. For this reason, very quick traditional surveys have been carried out and no-contact survey approach was applied to collect a big amount of data. For this purpose, over then twenty detailed DTMs of rock wall along the entire road, coupled to calibrated digital images were analysed with Rockscan software, specifically developed for measuring plane orientation, spacing and other geometrical characteristics of outcropping rock masses. This procedure made it possible to collect a large amount of highquality data: thousand orientation data and hundreds spacing data have been collected and analysed with statistical techniques. This procedure allowed the Authors to obtain results regarding stability condition of rock slopes, to estimate the volume of the rocky blocks (Ferrero et al, 2014) affected by potential detachment condition and to get information useful for the subsequent design and feasibility studies in terms of the safety on the investigated road axis and rockfall risk analysis.

\subsection{Case study}

As aforementioned, in the above Paragraph, the case study selected for the present research is the road of Vallone d'Elva. It has been chosen due to its morphology and its particular value as an environmental issue. The road takes its name from the village of Elva, sited in Maira Valley in the province of Cuneo (Italy). The historical centre is the 10th municipality for the altitude in Italy, $1700 \mathrm{~m}$ a.s.l.. It is famous for its richness of artworks and it is a tourist attractive - especially during the summer - due to its natural beauty and its characteristic breath-taking landscape view.

For these reasons, the connections with the low valley and the other villages have always been important for this area. The descent to the valley has always been difficult, especially due to the presence of snow in the winter months. Citizens and rural people have attempted many times during the years to design a road in order to connect Elva to the lower Maira Valley main road. Some documents of 1763 reported the necessity of an easier route and in 1838 a municipal resolution declared to design a path along "La Comba", the area today named "Il Vallone", sites along a secondary valley of the Macra's river, between Maira and Varaita Valleys. It was opened in 1934 as a path and in 1950 became suitable for vehicles (today it is named Strada
Provinciale - SP 104). The paved road is enclosed by walls of living rock and flanked by twelve tunnels dug into the rock.

Precisely because of this conformation, it was characterised by landslides and rock falls events causing long periods of isolation for the villages of Elva. The most critical landslide event was the one of 2014, after which the road was declared closed due to its dangerousness.

Today, the inhabitants of Elva claiming the re-opening of the road for its cultural and historical value and for touristic reasons and its attractiveness. Many cyclist and bikers cross the scenic road every year. Moreover, the other road (the SP 335), which is possible to travel to reach Elva, results longer (of $5 \mathrm{~km}$ ) and more articulated. For all these aspects and thanks to an agreement with the Elva municipality in order to consider some studies for the reopening of the road and its securing, an integrated 3D metric survey for the documentation and the analysis of the area has been performed by the Geomatics Group of the Polytechnic of Turin with the students of the Team DIRECT (Disaster RECovery Team) (Grasso et al., 2015). This initiative aims to contribute actively to the protection of the territory, of the architectural heritage and environmental, architectural and archaeological assets, during natural emergencies or in the case of goods subjected to dangers of even an ordinary, continuous type. Every year the team involves the students in training activity, both with frontal lessons and stages in the field.

Moreover, a geostructural survey for performing geomechanical analysis has been carried out by the Geomechanical Group of Polytechnic of Turin.

These surveys and the data collected are explained in the next Paragraphs.

\section{DATA ACQUiSITION}

\subsection{Topographic and photogrammetric acquisition data}

In the summer of 2019, a 3D integrated metric survey has been performed in the area of the road of Vallone d'Elva and in its villages and hamlets.

The Vallone route is a complex environment and for this reason, it was necessary to plan the acquisitions of data and the fieldwork. A multi-sensors and multi-scale survey with different techniques has been employed.

In order to cover all ten kilometres of the road, the survey was divided in three different areas, namely "High part of Road (HR)", "Low part of Road (LR)" and "Large Landslide (LL)", respectively, as shown in Figure 1.

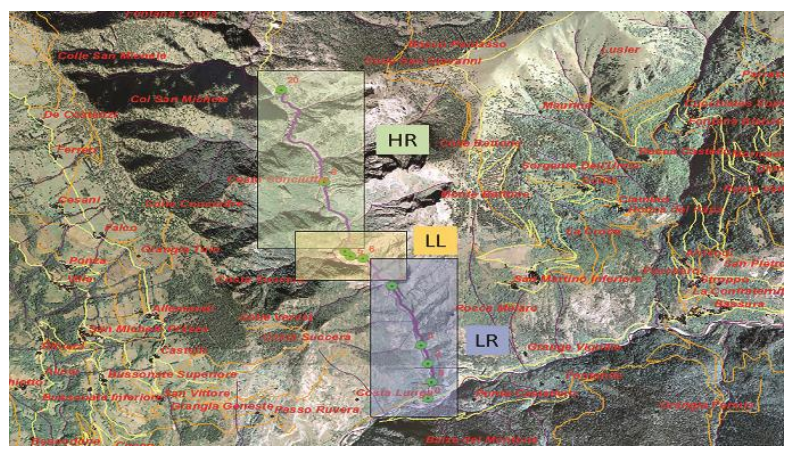

Figure 1. Representative areas of surveys

The first step, preliminary to all acquisitions, have been designed and measured the topographic network planned to georeference the different sets of data. We have been materialized on the ground 22 vertices that were measured with GNSS (Global Navigation Satellite System) techniques and traditional topographic techniques with Total Station (TS) in order to 
guarantee a rigorous approach in terms of accuracy and precision ( $\sigma_{\max }=3 \mathrm{~mm}$ in the vertical direction). The vertices coordinates have been measured through a geodetic GNSS receiver in static mode and, in a second phase, the network was calculated using the permanent stations of the national network. The coordinates have been estimated considering a multi-base solution (through the Leica Geo Office ${ }^{\circledR}$ software v.8.4) with stations of CORSs (Continuous Operating Reference Stations) (Snay \& Soler, 2011) network by Piedmont district like reported in Figure 2.
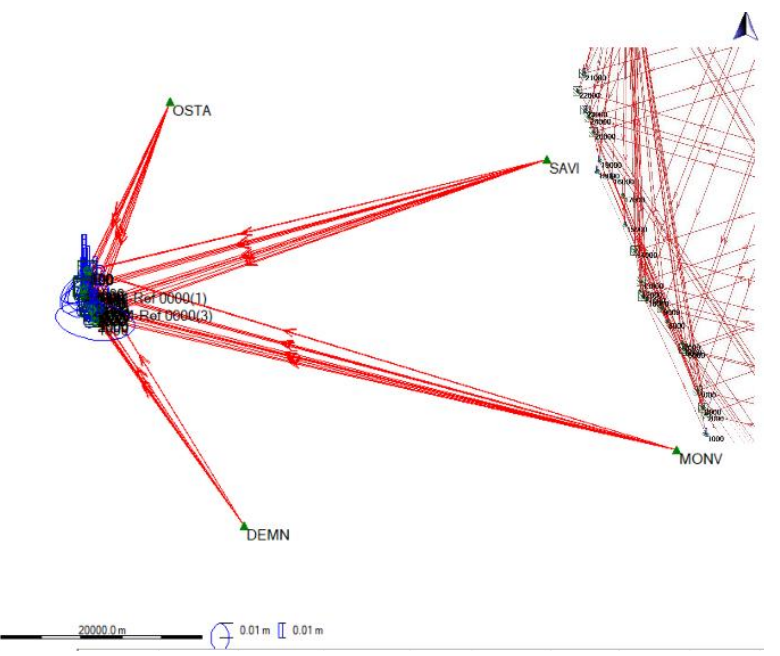

Figure 2. CORS constellations in Elva area

Subsequently, some photogrammetric control points have been acquired on markers, both on horizontal street surface and on vertical rock façades, with a few centimetres $\left(\sigma_{\max }=3 \mathrm{~cm}\right)$ coordinates precision using a fixed-phase ambiguity for all points. Moreover, 54 vertical markers and 120 natural target points have been measured using TS (Leica Image Station) located on the reference vertices. In the end, the data have been processed and adjusted in order to obtain the final coordinates: the RMSE (Root Mean Square Error) was less than $1 \mathrm{~cm}$.

These horizontal and vertical markers have been classified as GCPs (Ground Control Points) and CPs (Check Points) used to georefence the subsequent $3 \mathrm{D}$ post-processing data. It is important to note that both of them were mainly materialized along the road axis (within an area of 15 meters from its axis on both side), except some natural points, as evidenced by their distributions shown in the Table 1. This testifies the linear extent of our investigation area along the $10 \mathrm{~km}$ of Vallone d'Elva road development, like show in Figure 3.

\begin{tabular}{|c|c|c|}
\hline $\mathrm{N}^{\circ}$ topog. points & $\begin{array}{l}\mathrm{N}^{\circ} 30 \mathrm{~m} \text { topog. } \\
\text { Points }\end{array}$ & $\begin{array}{c}\% \text { 30m topog. } \\
\text { points }\end{array}$ \\
\hline 274 & 227 & 82,84 \\
\hline $\begin{array}{c}\text { Total Area } \\
{\left[\mathrm{km}^{2}\right]}\end{array}$ & $\begin{array}{c}\text { Area in } 30 \mathrm{~m} \\
{\left[\mathrm{~km}^{2}\right]}\end{array}$ & Area Ratio [\%] \\
\hline 0,688 & 0,1365 & 19,84 \\
\hline
\end{tabular}

Table 1. Statistics of linear extent surveys.

To perform a complete and multi-scale survey of the road, different sensors and techniques were employed, as well as UAVs, TLS (Terrestrial Laser Scanner), SLAM techniques (Simultaneous Localizations And Mapping) and CRP (CloseRange Photogrammetry), have been used.

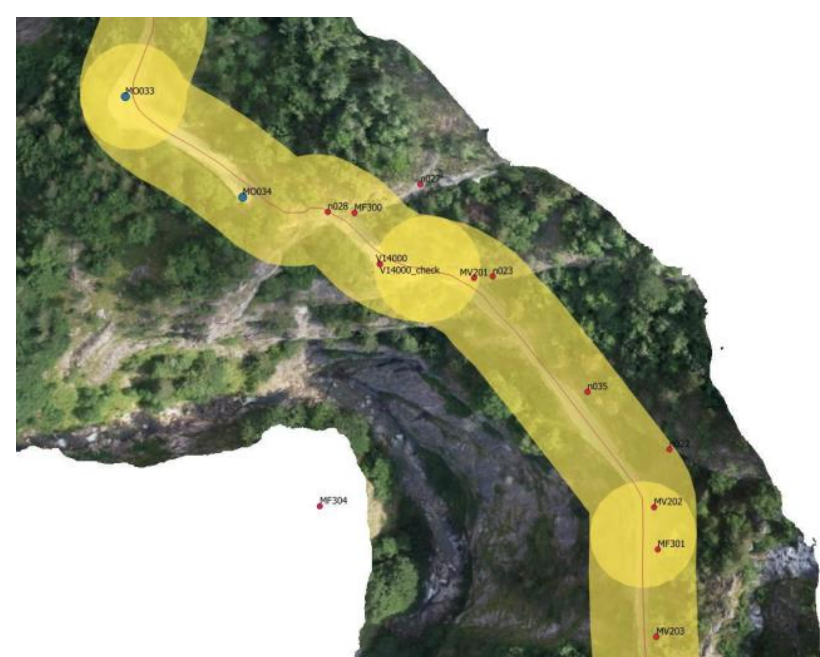

Figure 3. Shape and distribution of measured topographic points.

In this paper, we focused on photogrammetric data. The aerial images have been acquired using standard terrain resolution and accuracy criteria (Piras, Di Pietra, et al., 2017) and due to the morphology of the area, it has been chosen to perform manual flights with skilled UAV pilots to guarantee a higher level of safety. Commercial UAV has been used: DJI Phantom 4, with a FC6310 camera, 20 MP CMOS sensor, focal length of $8.8 \mathrm{~mm}$. Nadiral and oblique images have been combined for acquiring the vertical surface of rock façades, as shown in Table 2.

\begin{tabular}{|c|c|c|c|}
\hline & Nadir & Oblique & Total \\
\hline \multirow{3}{*}{ HR } & 3 flights & 5 flights 395 & 8 flights 900 \\
& 505 images & images & images \\
& 4 flights & 3 flights & 7 flights \\
LR & 340 images & 259 images & 599 images \\
& 2 flights & 2 flights & 4 flights \\
LL & 48 images & 137 images & 185 images \\
\hline
\end{tabular}

Table 2. UAV photogrammetric data.

During the surveys, multiple acquisitions of high-resolution images through terrestrial photogrammetry technique were carried out. This technique, applied along the rock walls of the SP 104, was performed using high-resolution cameras, such as NIKON D800E (24 mm focal length and 36,3 MP CMOS FullFrame sensor) and SONY ILCE-7RM3 (24 mm focal length and 42,4 MP CMOS Exmor R Full-Frame $35 \mathrm{~mm}$ sensor). The statistics about them are reported in Table 3.

\begin{tabular}{|c|c|c|}
\hline & $\mathrm{N}^{\circ}$ of strips & $\mathrm{N}^{\circ}$ of images \\
\hline HR & 4 & 2126 \\
LR & 3 & 1308 \\
\hline
\end{tabular}

Table 3. Terrestrial photogrammetric data.

The terrestrial approach has been employed to generate a complete reconstruction along the entire road-side envelop, with the diversification in HR and LR areas. 


\section{Photogrammetric data Processing}

The photogrammetric processing has been carried out with SfM algorithms using the commercial software AMS (Agisoft MetaShape Professional), dividing the total amount of the gathered data in two separated processing techniques: UAV and terrestrial images, inside the multiscale approach from small (UAV technique) to very large scale (terrestrial technique).

\subsection{UAV photogrammetric technique}

This process has been employed along whole Vallone d'Elva road, using both nadiral and oblique images, setting up the "high" level of accuracy of AMS (i.e. using the photos at the original size). Then, some GCPs - used for georeferencing 3D models and CPs to validate the obtained precision, have been collimated in all the images, obtaining the results in Table 4 and Table 5.

\begin{tabular}{|c|c|c|c|c|}
\hline n. GCPs & $\begin{array}{c}\Delta X \\
{[\mathrm{~mm}]}\end{array}$ & $\begin{array}{c}\Delta \mathrm{Y} \\
{[\mathrm{mm}]}\end{array}$ & $\begin{array}{c}\Delta \mathrm{Z} \\
{[\mathrm{mm}]}\end{array}$ \\
\hline HR & 17 & 39 & 29 & 53 \\
& & $\mathbf{1 6}$ & $\mathbf{1 3}$ & $\mathbf{1 7}$ \\
LL & 9 & 10 & 19 & 10 \\
& & $\mathbf{5}$ & $\mathbf{9}$ & $\mathbf{5}$ \\
LR & 13 & 20 & 15 & 34 \\
\hline
\end{tabular}

Table 4. UAV photogrammetric block - GCPs residual errors along Vallone d'Elva road.

\begin{tabular}{|c|c|c|c|c|}
\hline & n. CPs & $\begin{array}{c}\Delta X \\
{[\mathrm{~mm}]}\end{array}$ & $\begin{array}{c}\Delta \mathrm{Y} \\
{[\mathrm{mm}]}\end{array}$ & $\begin{array}{c}\Delta \mathrm{Z} \\
{[\mathrm{mm}]}\end{array}$ \\
\hline HR & 7 & 33 & 13 & 16 \\
& & $\mathbf{1 4}$ & $\mathbf{8}$ & $\mathbf{1 0}$ \\
LL & 4 & 12 & 7 & 10 \\
& & $\mathbf{8}$ & $\mathbf{5}$ & $\mathbf{7}$ \\
LR & 5 & 13 & 17 & 26 \\
& & $\mathbf{9}$ & $\mathbf{9}$ & $\mathbf{1 5}$ \\
\hline
\end{tabular}

Table 5. UAV photogrammetric block - CPs residual errors along Vallone d'Elva road.

The second phase expected generation of three 3D dense point clouds, setting-up an "high" details level of AMS (which means that the original images were downscaled by a factor of 4 -i.e. 2 times by each side), in order to obtain some products suitable for a large-scale purpose (1:200) with a specify density, as shown in Table 6.

\begin{tabular}{|c|c|c|c|}
\hline LR & $\begin{array}{c}\mathrm{N}^{\circ} \text { points } \\
\text { [millions] }\end{array}$ & $\begin{array}{c}\text { Processing } \\
\text { time [hh:mm] }\end{array}$ & $\begin{array}{c}\text { Density } \\
\text { [points/dm }{ }^{2} \text { ] }\end{array}$ \\
\hline LL & 199 & $05: 49$ & 8 \\
HR & 268 & $00: 24$ & 10 \\
\end{tabular}

Table 6. UAV dense point clouds statistics.

High density point clouds (about 1 point each $4 \mathrm{~cm}$ ) and a moderate level of noise have been obtained: some noisy points, caused by vegetation and border effects have been removed manually. The triangulated 3D models have been obtained using the setting "high" of AMS (i.e. using 1/5 of the number of points of the source dense point clouds), generating high resolution meshes in terms of faces and vertices number, as summarized in Table 7.

\begin{tabular}{|c|c|c|c|}
\hline LR & $\begin{array}{c}\text { N. faces } \\
\text { [millions] }\end{array}$ & $\begin{array}{c}\text { N. vertices } \\
\text { [millions] }\end{array}$ & $\begin{array}{c}\text { Proc. time } \\
\text { [hh:mm] }\end{array}$ \\
LL & 40 & 120 & $02: 04$ \\
HR & 0,1 & 0,1 & $01: 26$ \\
& 53 & 27 & $02: 09$ \\
\hline
\end{tabular}

Table 7. UAV mesh statistics.

The final steps had regarded the generation of the DSMs and the relative orthophotos in WGS84 - UTM $32 \mathrm{~N}$ coordinates system starting by the relative meshes (detailed in Table 8), as shown in Figure 4.

\begin{tabular}{|c|c|c|}
\hline & $\begin{array}{c}\text { DSM } \\
\text { process. time [mm:ss] }\end{array}$ & $\begin{array}{c}\text { Orthophotos } \\
\text { process. time [mm:ss] }\end{array}$ \\
\hline LR & $02: 44$ & $25: 58$ \\
LL & $00: 09$ & $00: 14$ \\
HR & $03: 39$ & $33: 50$ \\
\hline \multicolumn{2}{|c|}{ Table 8. DSMs and orthophotos statistics in UAV } \\
photogrammetric process.
\end{tabular}

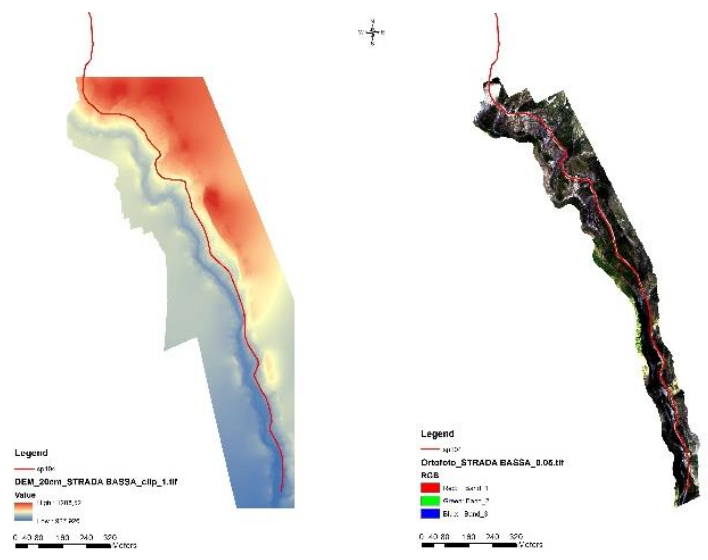

Figure 4. LR example of DSM and orthophoto.

Indeed, the use of such high-detail clouds in complex environments with slopes and irregularities, makes it necessary to experiment "ad-hoc" workflow to detected ground points and other features, such as trees and buildings (Spanò et al., 2018). In this case, to obtain a DTM (Digital Terrain Model) a semiautomatic classification approaches with AMS has been tested. The results of classification were quite satisfactory: $75 \%$ of the vegetation points were correctly detected, while were wrongly classified ground about $11 \%$, and the rest was unclassified; besides, $85 \%$ of rock wall were correctly detected as ground, while $9 \%$ were wrongly classified like buildings in "quasi" vertical parts. In the following Figure 5 an example and the critical issues found, are reported.

Starting from the ground classify points obtained, 3D surfaces have been generated to compute a DTM.

\subsection{Terrestrial photogrammetric technique}

The terrestrial photogrammetric process has been made by SfM approach within the multiscale process: in fact, the rockwall flanks have been reconstructed in a large scale (1:200) along the $10 \mathrm{~km}$ of Vallone d'Elva road. The acquired images have been took using a particular pattern (Figure 6): parallel to the rockwall 
flank and with $45^{\circ}$ on the left and on the right along the road with a possible maximum distance from the flanks to optimize the resolution.

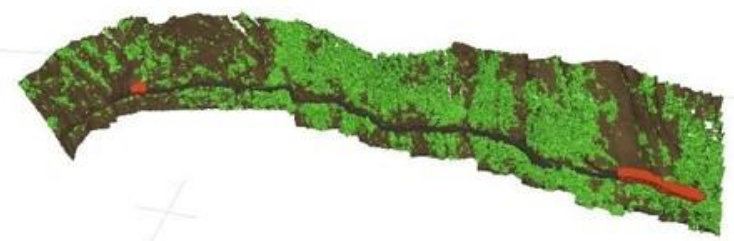

(a)

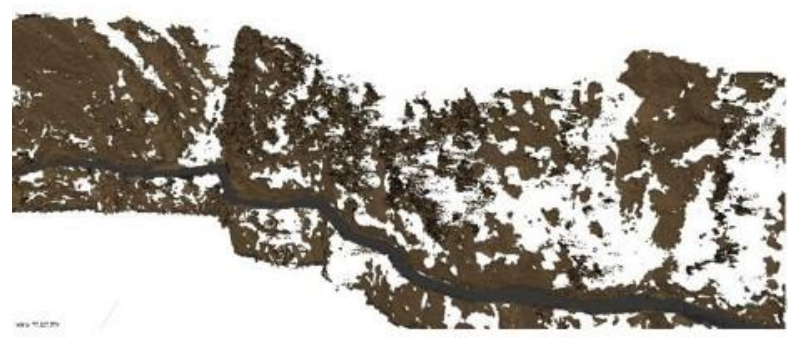

(b)

Figure 5. a) Semi-automatic classification in AMS; b) Critical issues found cause of complex and steep geography. Red, green, brown and black points represent building, vegetation, ground and road respectively.

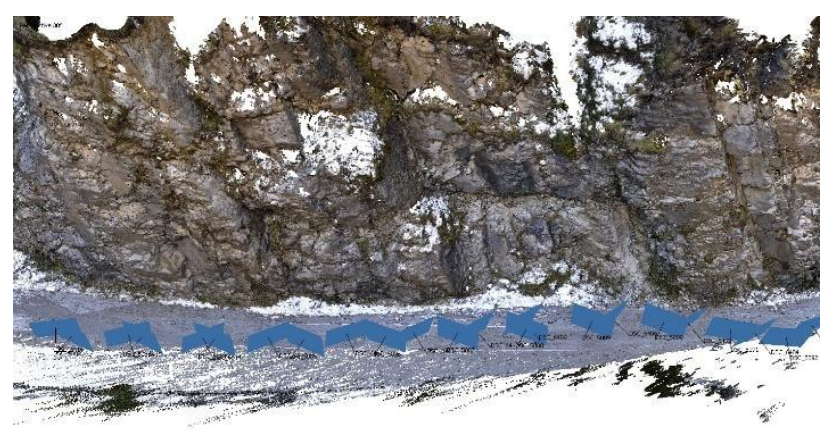

Figure 6. Terrestrial photogrammetric images pattern.

Like UAV photogrammetric data processing, the models have been set on a "high" level of accuracy of AMS, using some GCPs for georeferencing and CPs to validate the obtained precision. Then, these have been collimated in all the images, obtaining the results shown in Table 9 and Table 10.

\begin{tabular}{|c|c|c|c|c|}
\hline n. GCPs & $\begin{array}{c}\Delta \mathrm{X} \\
{[\mathrm{mm}]}\end{array}$ & $\begin{array}{c}\Delta \mathrm{Y} \\
{[\mathrm{mm}]}\end{array}$ & $\begin{array}{c}\Delta \mathrm{Z} \\
{[\mathrm{mm}]}\end{array}$ \\
\hline HR & 21 & 29 & 20 & 42 \\
& & $\mathbf{1 3}$ & $\mathbf{9}$ & $\mathbf{1 5}$ \\
LR & 14 & 17 & 16 & 31 \\
& & $\mathbf{6}$ & $\mathbf{6}$ & $\mathbf{1 1}$ \\
\hline
\end{tabular}

Table 9. Terrestrial photogrammetric block - GCPs residual errors along Vallone d'Elva road.

\begin{tabular}{|c|c|c|c|c|}
\hline n. CPs & $\begin{array}{c}\Delta \mathrm{X} \\
{[\mathrm{mm}]}\end{array}$ & $\begin{array}{c}\Delta \mathrm{Y} \\
{[\mathrm{mm}]}\end{array}$ & $\begin{array}{c}\Delta \mathrm{Z} \\
{[\mathrm{mm}]}\end{array}$ \\
\hline HR & 11 & $\begin{array}{c}225 \\
\mathbf{7 0}\end{array}$ & $\begin{array}{c}392 \\
\mathbf{8 7}\end{array}$ & $\begin{array}{c}119 \\
\mathbf{3 7}\end{array}$ \\
$\mathrm{LR}$ & 7 & 12 & 15 & 35 \\
& & $\mathbf{9}$ & $\mathbf{1 0}$ & $\mathbf{1 8}$ \\
\hline
\end{tabular}

Table 10. Terrestrial photogrammetric block - CPs residual errors along Vallone d'Elva road.

As can be seen from the data shown by the HR CPs, the presence of snow in the images acquired during the survey of November 2019 , has been caused a slight loss of accuracy in the model about $6 \mathrm{~cm}$ mean.

Furthermore, two dense point clouds have been generated with "high" level of details, as shown in Table 11.

\begin{tabular}{|c|c|c|c|}
\hline & $\begin{array}{c}\mathrm{N}^{\circ} \text { points } \\
{[\text { millions] }}\end{array}$ & $\begin{array}{c}\text { Processing } \\
\text { time [hh:mm] }\end{array}$ & $\begin{array}{c}\text { Density } \\
\left.\text { [points/dm }{ }^{2}\right]\end{array}$ \\
\hline HR & 2668 & $160: 24$ & 526 \\
LR & 772 & $28: 12$ & 192 \\
\hline
\end{tabular}

Table 11. Terrestrial photogrammetric dense point clouds statistics.

The aforementioned data show how the terrestrial technique has given us greater accuracy in terms of number of points and density. It is a consequence, unlike UAV data processing, of areas much more narrows (an order of magnitude) along a thin band of road about 10-15 meters wide (Table 12), in addition to the greater overlap of the acquired images.

\begin{tabular}{|c|c|c|}
\hline HR & $\begin{array}{c}\text { UAV area } \\
{\left[\mathrm{km}^{2}\right]}\end{array}$ & $\begin{array}{c}\text { Terr. area } \\
{\left[\mathrm{km}^{2}\right]}\end{array}$ \\
\hline LR & 0.434 & 0.041 \\
0.254 & 0.027 \\
\hline
\end{tabular}

Table 12. UAV - Terrestrial data comparison.

\subsection{Road-side orthophotos: a new terrestrial product}

In order to obtain a larger scale terrestrial data, we have been produced 16 vertical orthophotos on the respective rockmasses investigated by geomechanical survey, taking advantage of the algorithms implemented in AMS.

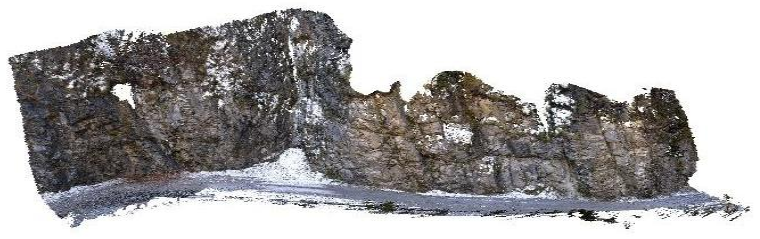

Figure 7. Example of "vertical" terrestrial dense point cloud.

An ad hoc procedure allowed us to compute 16 high resolution dense point clouds (setting-up "high" details level during the alignment and building phases), in order to perform many 3D surfaces (named meshes), also with "high" details level, as show an example in Figure 7 and Figure 8 respectively.

Finally, the vertical orthophotos have been created starting from the respective meshes, with a millimetric resolution (mean about $4 \mathrm{~mm}$ each), how is reported in Figure 9. 


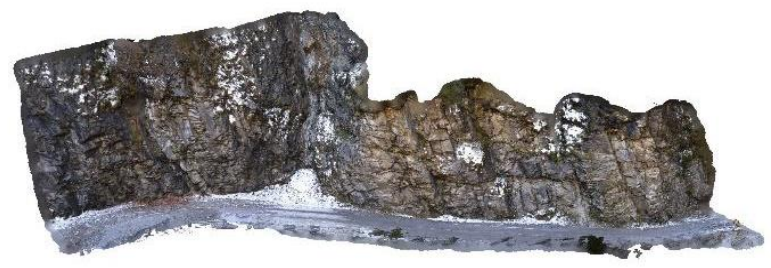

Figure 8. Example of "vertical" terrestrial mesh.

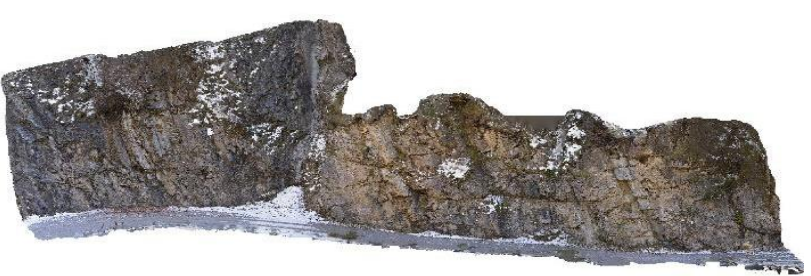

Figure 9. Example of "vertical orthophotos".

This innovative product has been used to employ the traditional UAV and terrestrial photogrammetric processes for a better understanding and definition of the landscape environment about this specific case study. Moreover, associated with the geomechanical surveys and the related data processing (see next paragraph), they allowed a more detailed investigation about many geomechanical features (such as sliding mechanisms, rocksuch as sliding mechanisms, rock-wall fracture analysis, etc.) of the investigated rock masses.

\section{ROCKMASS NO-CONTACT GEOSTRUCTURAL SURVEY}

The definition of the stability condition of a rock mass and the identification of unstable blocks need, firstly, a geostructural surveys able to collect data about geometrical features of discontinuities as spatial orientation, spacing and persistence (ISRM, 1981). Getting these parameters allow the definition of the size and shape of the rocky block and their kinematic conditions. Usually these surveys were made along scanlines placed directly on the rock walls and using geological compass. In the studied case, the unstable conditions are so widespread along the entire road that they do not allow this operation under safe conditions. For this reason, very quick traditional surveys have been carried out and no-contact survey approach was applied to collect a big amount of data in 20 specific sites along the $9 \mathrm{~km}$ of road.

Eleven outcropping rock masses located along the High part of road (HR), nine along the LR and one at the LL have been subject of geostructural survey with both quick traditional and no-contact techniques. For the latter, 20 georeferenced DTMs have been specifically created starting from the UAV and terrestrial digital images and by using the commercial software AMS (Agisoft MetaShape). In order to reproduce also the smaller discontinuity surfaces the DTMs must characterized by a hight density of points, sometimes less than $1 \mathrm{pt} / \mathrm{cm}^{2}$, depending on the area of outcropping surface.

With this aim the DTMs have built rock surfaces with limited dimensions: about 30-40 m length and $15 \mathrm{~m}$ high; the most of the surveyed rock masses did not include any GCPs or CPs reported in paragraph 2.1; for this reason, each DTM have been georeferenced by defining several natural points (markers in Figure 10) on the digital images and by getting their coordinates directly from the general DSM of the entire road.

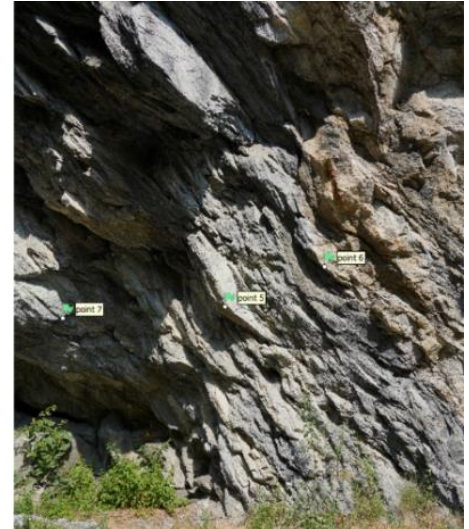

Figure 10. Examples of natural markers used for georeferencing the specific DTMs.

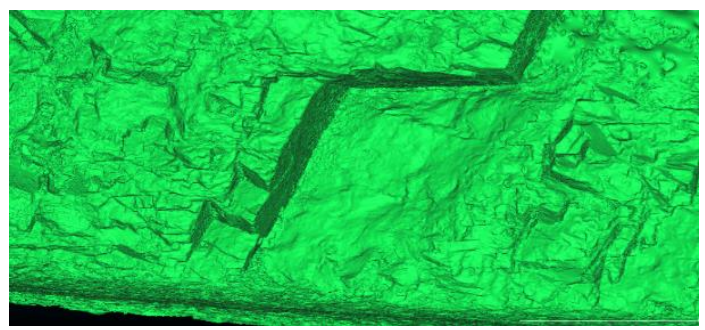

a)

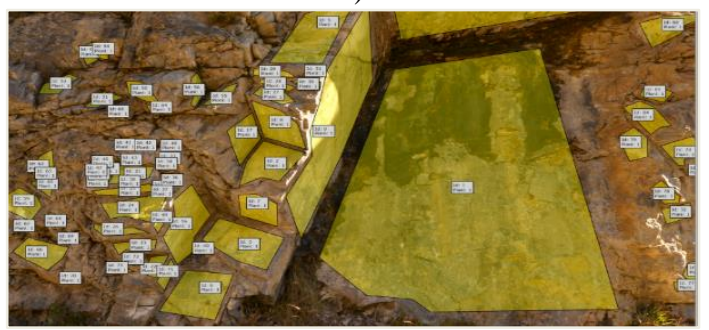

b)

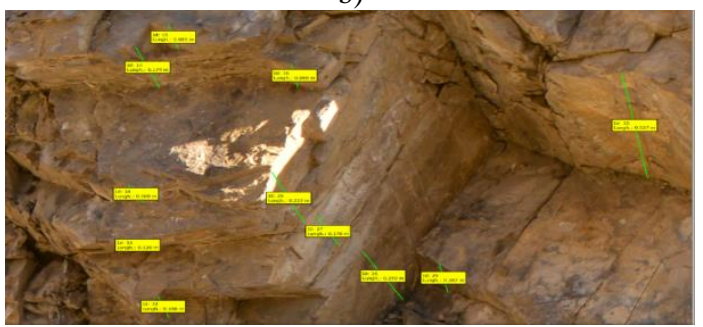

c)

Figure 11.Geometrical features of discontinues collected by Rockscan software: a) Model; b) discontinuity planes; c) spacing.

The DTMs, the oriented digital images and the camera calibrations parameters have been used in Rockscan software (Ferrero et al., 2019) specifically developed for measuring plane orientation and spacing (Figure 11). In this way more than 2560 planes orientation data and 1000 spacing measure have been collected allowing the authors to carry out kinematic analysis to evaluate how the stability degree of the rock mass change along the road. For each slope a stereographic projection of the collected plane has allow the identification of the set of discontinuities and the orientation of their main plane; the spacing measure has allowed the definition of the shape and volume of the detachable blocks and their kinematic condition (any movement, rock fall, planar slide or wedge slide). In the attached file (Figure 12), the results obtained for one of the 20 rock slope analysed is reported. 


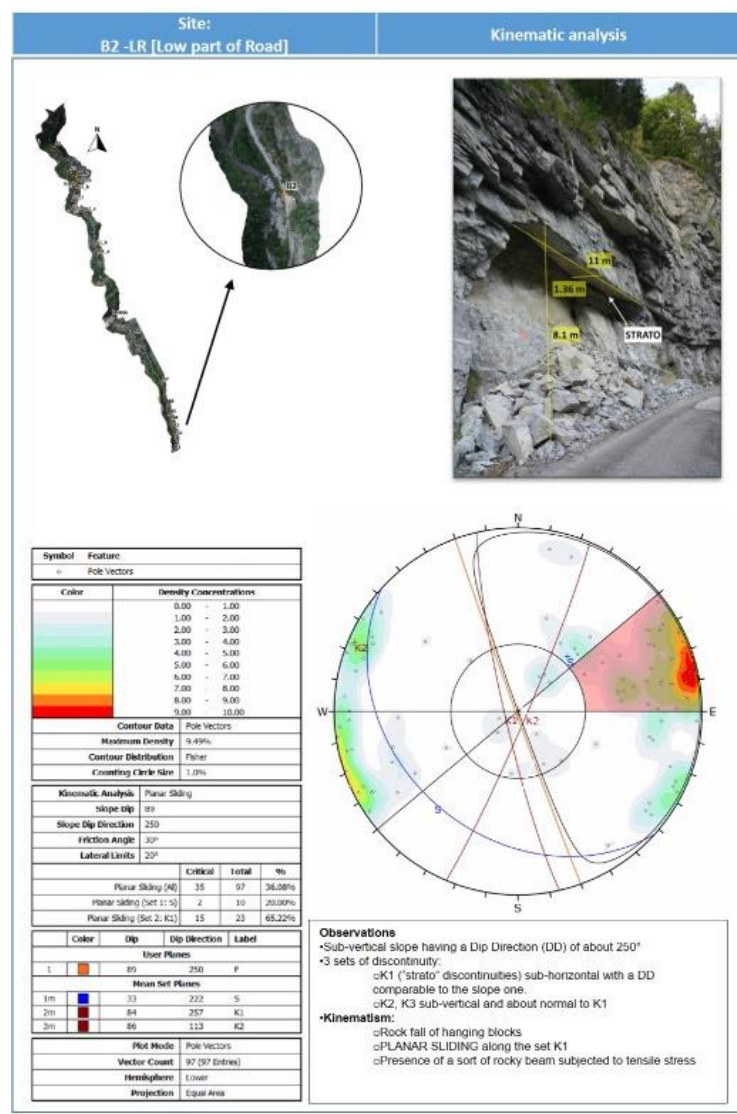

Figure 12. Example of stereographic projection of the collected plane for discontinuities sets identification.

\section{RESULTS AND TECHNIQUES INTEGRATION}

In order to identify the critical issues related to landslide hazard in the complex orographic environment of the Vallone d'Elva, the aforementioned photogrammetric and geomechanical investigation techniques have been performed using a multiscale approach. The interaction and integration between them has allowed us to obtain even more detailed results. Specifically, the UAV photogrammetry data processing provided dense point clouds on a small scale (divided into the 3 portions of road mentioned above, i.e. HR, LL, LR) having an average density of 8 points $/ \mathrm{dm}^{2}$, reflecting on a centimetre GSD (average equal to 4 $\mathrm{cm}$ ) of the DSMs and orthophotos produced. To perform the stability analyses, the dense point clouds semi-automatic classification allowed us to obtain DTMs with an appreciable quality: about $85 \%$ of rockwalls have been detected as ground. However, in order to obtain an even more defined product, terrestrial photogrammetry has allowed us to generate dense point clouds with very high density (mean equal to 359 points $/ \mathrm{dm}^{2}$ ). This consideration led us to compute 16 threedimensional models depicting as many rock masses placed on the investigated road flanks of the road along its development to Elva village. The originated $3 \mathrm{D}$ surfaces show a millimeter accuracy (mean $3 \mathrm{~mm}$ ); from these products, new vertical orthophotos with average millimeter resolution have been developed.

The DTMs, the oriented digital images and the camera calibrations parameters allow to collect, using specific software, a big amount of geometrical data of the discontinuity planes characterizing the rock masses. Being these measures required for any design approach for the landslide risk mitigation and being not possible to guarantee safe condition of the operators in any situation, this type of approach appears as the only one useful and applicable.

\section{Conclusion}

The study of environmental vulnerabilities linked to landslide hazard along the SP104 of the Vallone d'Elva led us to adopt the most advanced survey techniques and methods.

The integration between UAV and terrestrial photogrammetry techniques has been allowed us to obtain an even more details degree useful to support the geomechanical surveys, which were carried out in situ and in the laboratory through an ad hoc postprocessing (using Rockscan software).

These technologies have provided data capable to descript and define a complete and precise geomechanical detailed analysis in an area with complex orography and inaccessible in many places of it, such as the investigated case study of the Vallone d'Elva. These data have been returned a detailed reconstruction of the environmental risk due to the high landslide hazard along the SP104, like was witnessed by 2014 event.

\section{ACKNOWLEDGEMENTS}

The authors would like to thank the Elva municipality, in particularity Mr. Fulcheri (Mayor) and Mr. Allocco (Alderman) for the organization, preparation and passion about Elva management. We would like to thank the DIRECT Group Elva 2019: the students Peaquin Fabiana, Moschini Tatiana, Graziano Samuele, Tofalo Federica, Zanti Davide, Oggero Marco, Rivero Nicolò, Migliore Matteo, Roasio Alberto, Traore Ammj, Jonnalagadda Chowdary Neeraj, Fasano Francesca, Grasso Paolo, Colona Giacomo, Cortese Guglielmo, Comino Jessica, Tahmasbi Mashid; the Tutors Prof. Spanò Nannina, Prof. Tonolo Fabio Giulio, Prof. Chiabrando Filiberto, Maschio Paolo, Toniolo Serena, Teppati Losè Lorenzo, Di Pietra Vincenzo, Grasso Nives, Calantropio Alessio, Abbate Emilio, Patrucco Giacomo, Prof. Lingua Andrea, Colucci Elisabetta.

\section{REFERENCES}

Ahmad, A., Samad, A. M., 2010. Aerial mapping using high resolution digital camera and unmanned aerial vehicle for Geographical Information System. In $20106^{\text {th }}$ International Colloquium on Signal Processing \& its Applications. https://doi.org/10.1109/cspa.2010.5545303.

Aicardi, I., Chiabrando, F., Grasso, N., Lingua, A. M., Noardo, F., Spanò, A., 2016. UAV photogrammetry with oblique images: first analysis on data acquisition and processing. In ISPRS International Archives of the Photogrammetry, Remote Sensing and Spatial Information Sciences (Vols. XLI- B1, pp. 835-842). https://doi.org/10.5194/isprs-archives-xli-b1-835-2016.

Artese, G., Perrelli, M., Artese, S., Manieri, F., Principato, F., 2014. The contribute of geomatics for monitoring the great landslide of Maierato, Italy. In ISPRS - International Archives of the Photogrammetry, Remote Sensing and Spatial Information Sciences (Vols. XL- 5/W3, pp. 15-20). https://doi.org/10.5194/isprsarchives-xl-5-w3-15-2013.

Bemis, S. P., Micklethwaite, S., Turner, D., James, M. R., Akciz, S., Thiele, S. T., Bangash, H. A., 2014. Ground-based and UAVBased photogrammetry: A multi-scale, high-resolution mapping tool for structural geology and paleoseismology. In Journal of Structural Geology (Vol. 69, pp. 163-178). https://doi.org/10.1016/j.jsg.2014.10.007. 
Caroti, G., Martínez-Espejo Zaragoza, I., Piemonte, A., 2015. Accuracy assessment in structure from motion 3D reconstruction from UAV-born images: the influence of the data processing methods. In ISPRS - International Archives of the Photogrammetry, Remote Sensing and Spatial Information Sciences (Vols. XL- 1/W4, pp. 103-109). https://doi.org/10.5194/isprsarchives-xl-1-w4-103-2015.

Castagnetti, C., Bertacchini, E., Corsini, A., Capra, A. 2013. Multi-sensors integrated system for landslide monitoring: critical issues in system setup and data management. In European Journal of Remote Sensing (Vol. 46, Issue 1, pp. 104-124). https://doi.org/10.5721/eujrs20134607.

Castagnetti, C., Bertacchini, E., Corsini, A., Rivola, R., 2014. A reliable methodology for monitoring unstable slopes: the multiplatform and multi-sensor approach. In Earth Resources and Environmental Remote Sensing/GIS Applications V. https://doi.org/10.1117/12.2067407.

Chiabrando, F., Donadio, E., Rinaudo, F., 2015. SfM for Orthophoto to Generation: A Winning Approach for Cultural Heritage Knowledge. In ISPRS - International Archives of the Photogrammetry, Remote Sensing and Spatial Information Sciences (Vols. XL- 5/W7, pp. 91-98). https://doi.org/10.5194/isprsarchives-xl-5-w7-91-2015.

Corsini, A., Ronchetti, F., Bertacchini, E., Bonacini, F., Calicetti, P., Capra, A., Castagnetti, C., Piantelli, E., Caputo, G., Truffelli, G., 2013. Large-Scale Slope Instability Affecting SS63 Near the Cerreto Pass (Northern Apennines, Italy). In Landslide Science and Practice (pp. 231-237). https://doi.org/10.1007/978-3-64231319-6_32.

Ferrero, A.M., Forlani, G.F., Roncella, R. and Voyat, H.I., 2009. Advanced geostructural survey methods applied to rock mass characterization. Rock Mechanics and Rock Engineering 42 (4), pp. 631-665.

Ferrero AM, Migliazza MR, Umili G., 2014. Rock mass characterization by means of advanced survey methods. Keynote lecture. In: Rock engineering and rock mechanics: structures in and on rock masses - proceedings of EUROCK 2014, ISRM European regional symposium, Vigo, Spain, 27-29 May 2014, pp 17-27, ISBN 978-1-138-00149-7

Grasso, N., (2015). DIsaster REcovery Team (DIRECT): formazione e attività del team studentesco del Politecnico di Torino per la gestione delle emergenze. In: Bollettino della Società Italiana di Fotogrammetria e Topografia. - issn 1721971x. - stampa, (pp. 70-76).

Jiang, R., Jáuregui, D. V., White, K. R., 2008. Close-range photogrammetry applications in bridge measurement: Literature review. In Measurement (Vol. 41, Issue 8, pp. 823-834). https://doi.org/10.1016/j.measurement.2007.12.005.

Kalbermatten, M., Van De Ville, D., Turberg, P., Tuia, D., Joost, S., 2012. Multiscale analysis of geomorphological and geological features in high resolution digital elevation models using the wavelet transform. In Geomorphology (Vol. 138, Issue 1, pp. 352-363). https://doi.org/10.1016/j.geomorph.2011.09.023.

Li, Z., Zhu, C., Gold, C., 2004. Digital Terrain Modeling: Principles and Methodology. CRC Press.
Mancini, F., Castagnetti, C., Rossi, P., Dubbini, M., Fazio, N., Perrotti, M., Lollino, P., 2017. An Integrated Procedure to Assess the Stability of Coastal Rocky Cliffs: From UAV Close-Range Photogrammetry to Geomechanical Finite Element Modeling. In Remote Sensing (Vol. 9, Issue 12, p. 1235). https://doi.org/10.3390/rs9121235.

Marceau, D. J., Hay, G. J., 1999. Remote Sensing Contributions to the Scale Issue. In Canadian Journal of Remote Sensing (Vol. 25, Issue 4, pp. 357-366). https://doi.org/10.1080/07038992.1999.10874735.

Masiero, A., Chiabrando, F., Lingua, A. M., Marino, B. G., Fissore, F., Guarnieri, A., Vettore, A., 2019. 3D modeling of Girifalco fortress. In ISPRS - International Archives of the Photogrammetry, Remote Sensing and Spatial Information Sciences (Vols. XLII- 2/W9, pp. 473-478). https://doi.org/10.5194/isprs-archives-xlii-2-w9-473-2019.

Niethammer, U., James, M. R., Rothmund, S., Travelletti, J., Joswig, M., 2012. UAV-based remote sensing of the SuperSauze landslide: Evaluation and results. In Engineering Geology (Vol. 128, pp. 2-11). https://doi.org/10.1016/j.enggeo.2011.03.012.

Piras, M., Di Pietra, V., Visintini, D., 2017. 3D modeling of industrial heritage building using COTSs system: test, limits and performances. In ISPRS - International Archives of the Photogrammetry, Remote Sensing and Spatial Information Sciences (Vols. XLII- 2/W6, pp. 281-288). https://doi.org/10.5194/isprs-archives-xlii-2-w6-281-2017.

Piras, M., Taddia, G., Forno, M. G., Gattiglio, M., Aicardi, I., Dabove, P., Lo Russo, S., Lingua, A., 2017. Detailed geological mapping in mountain areas using an unmanned aerial vehicle: application to the Rodoretto Valley, NW Italian Alps. In Geomatics, Natural Hazards and Risk (Vol. 8, Issue 1, pp. 137149). https://doi.org/10.1080/19475705.2016.1225228.

Snay, R. A., Soler, T., 2011. Continuously Operating Reference Station (CORS): History, Applications, and Future Enhancements. In CORS and OPUS for Engineers (pp. 1-10). https://doi.org/10.1061/9780784411643.ch01.

Spanò, A., Sammartano, G., Tunin, F. C., Cerise, S., Possi, G., 2018. GIS-based detection of terraced landscape heritage: comparative tests using regional DEMs and UAV data. In Applied Geomatics (Vol. 10, Issue 2, pp. 77-97). https://doi.org/10.1007/s12518-018-0205-7.

Spreafico, M. C., Perotti, L., Cervi, F., Bacenetti, M., Bitelli, G., Girelli, V. A., Mandanici, E., Tini, M. A., Borgatti, L., 2015. Terrestrial Remote Sensing techniques to complement conventional geomechanical surveys for the assessment of landslide hazard: The San Leo case study (Italy). In European Journal of Remote Sensing (Vol. 48, Issue 1, pp. 639-660). https://doi.org/10.5721/eujrs20154835.

Watts, A. C., Ambrosia, V. G., \& Hinkley, E. A., 2012. Unmanned Aircraft Systems in Remote Sensing and Scientific Research: Classification and Considerations of Use. In Remote Sensing (Vol. 4, Issue 6, pp. 1671-1692). https://doi.org/10.3390/rs4061671. 